\title{
Decreased choriocapillaris perfusion following surgical excision of choroidal neovascular membranes in age-related macular degeneration
}

Ma'an A Nasir, Ilene Sugino, Marco A Zarbin

\begin{abstract}
Aims/background-To evaluate macular changes following surgical excision of subfoveal choroidal neovascular membranes (CNVs) in age-related macular degeneration (AMD).

Methods-The clinical records, fluorescein angiograms, and CNV histopathology of 12 patients with AMD who underwent surgical excision of subfoveal $\mathrm{CNV}$ were reviewed.

Results-New areas of decreased choriocapillaris perfusion were noted by fluorescein angiography in the previous location of the CNV in $8 / 12(75 \%)$ cases. Surgically excised tissue contained retinal pigment epithelium (RPE) in 11/11 specimens and choriocapillaris in $1 / 11$ specimen studied. Conclusions-Choriocapillaris atrophy may partly underlie the limited visual outcome following subfoveal surgery for AMD. Abnormal choriocapillaris perfusion following CNV excision may be due to pre-existing choriocapillaris atrophy, to choriocapillaris damage or removal at the time of surgery, or to RPE removal at surgery with abnormal RPE repopulation of the dissected area and subsequent choriocapillaris degeneration.

(Br F Ophthalmol 1997;81:481-489)
\end{abstract}

The Macular Photocoagulation Study Group (MPS) showed that laser photocoagulation is better than no therapy for selected extra-, juxta-, and subfoveal choroidal neovascular membranes (CNVs) in age-related macular degeneration (AMD). ${ }^{1-5}$ Two to 5 years after treatment, however, the visual outcome is poor, usually ranging from $20 / 100$ to $20 / 400$, and the cumulative rate of $\mathrm{CNV}$ persistence and recurrence is high, ranging between 50 and $60 \% .^{5-8}$ Furthermore, many patients are not eligible for laser treatment.

Limitations in laser therapy have stimulated interest in alternative treatments for exudative AMD such as $\alpha$ interferon therapy, teletherapy, and surgical excision of CNVs. ${ }^{9-14}$ Visual recovery following surgery for subfoveal CNV in patients with AMD is disappointing. Results from uncontrolled series indicate that few patients experience substantial visual improvement, many are unchanged, and some see worse following CNV excision. ${ }^{9-12}$ Lack of substantial improvement after surgery could be due to preoperative retinal degeneration induced by the exudative process, trauma during
CNV excision, postoperative retinal and retinal pigment epithelial (RPE) changes, or some combination of these factors.

We reviewed the clinical records, including serial fluorescein angiograms and the histopathology of the excised tissue, of 12 patients with AMD who underwent surgical excision of subfoveal CNVs to try to determine the aetiology of the poor visual outcome in these cases.

\section{Materials and methods}

The clinical records of all patients who underwent surgical excision of subfoveal CNVs between January 1991 and August 1993 were reviewed. All patients had visual acuity $\leqslant 20 /$ 200 secondary to subfoveal CNV in the setting of AMD. Each patient was offered the option of observation, laser treatment if eligible according to MPS criteria, referral for $\alpha$ interferon therapy, or surgical CNV excision. All patients underwent pre- and postoperative evaluations which included measurement of best corrected visual acuity using Snellen and Bailey-Lovie charts and serial fluorescein angiography. Visual acuity was assessed by individuals experienced in low vision refraction who were not part of the surgical team. Two of the 14 patients who underwent submacular surgery were excluded from this report. One of the two patients developed a retinal detachment involving the macula before a postoperative angiogram was obtained, and one patient developed a recurrent CNV 7 weeks after surgery and is the subject of a separate report. Impaired choriocapillaris perfusion was judged to be present if choriocapillaris filling was delayed until the early venous filling phase of the angiogram and non-perfusion was judged to be present if the filling defect persisted into the late venous phase of the angiogram. CNV dimensions were recorded by measuring the largest horizontal and vertical dimensions of the CNV as determined with a reticle and the preoperative fluorescein angiogram. The horizontal diameter of the optic disc was assumed to be $1500 \mu \mathrm{m}$. Specimens from 11 eyes were studied histologically. One specimen was lost during processing.

\section{SURGICAL TECHNIQUE}

All patients were operated on by the same surgeon (MAZ) using the approach described by Thomas and Kaplan. ${ }^{15} \mathrm{~A}$ conventional three port vitrectomy was performed. The posterior hyaloid was excised in all but two cases (nos 2, 4). The retina overlying the superior edge of
Accepted for publication 10 March 1997 
the $\mathrm{CNV}$ was diathermised in most cases to provide immediate access to the CNV upon entering the subretinal space. A small amount of balanced salt solution (less than $0.5 \mathrm{ml}$ ) was injected into the subretinal space to ensure there were no retina-CNV adhesions and to protect the sensory retina during the dissection and removal of the CNV. If adhesions were encountered (cases $2,4,5,7$ ), the sharp edge of a bent 1.5 inch 30 gauge needle was used to separate the retina and CNV. Despite this manoeuvre, macular hole $(\leqslant 100 \mu \mathrm{m})$ formation not involving the centre of the fovea occurred in three cases (nos $2,4,7$ ). If a well defined edge of the CNV was visible, it was grasped and elevated with intraocular forceps. If an edge was not apparent, the RPE overlying the superior edge of the CNV was incised with the tip of the bent 30 gauge needle to develop a cleavage plane between the $\mathrm{CNV}$ and adjacent tissue using the projected preoperative fluorescein angiogram to direct the incision. With the edge of the CNV grasped, gentle side to side traction was applied, and the CNV separated gradually from the surrounding RPE. CNV excision was performed while the intraocular pressure was elevated sufficiently to produce central retinal artery pulsation for no longer than 10 minutes. CNV excision was associated with mild bleeding in two cases (nos 11, 12). One patient (case 11) used coumadin for chronic atrial fibrillation $(\mathrm{PT} / \mathrm{PTT}=14 / 32$ preoperatively (normal 10-13/24-39)), and choriocapillaris was present in the excised tissue. In two cases (nos 7,8 ) subretinal blood was present preoperatively, and some remained at the end of surgery despite attempts to wash it out. Tissue plasminogen activator (TPA) was infused subretinally $(50 \mu \mathrm{g} / 0.1 \mathrm{ml}, 0.05 \mathrm{ml}$ used) to evacuate significant subretinal blood in one case (no 8).

The CNV was removed as a single piece of tissue in all cases. The configuration of the excised tissue bore a remarkable resemblance to the entire $\mathrm{CNV}$ as judged by the preoperative fluorescein angiogram, including both classic and occult components. Usually, the vitreous cavity was washed out for 3-5 minutes to remove any liberated RPE. A fluid-air exchange was performed flattening the retina completely. In most cases (nos 1-9), endolaser treatment was applied around the retinotomy, and a non-expansile concentration of $\mathrm{SF}_{6}$ (phakic patients) or $\mathrm{C}_{3} \mathrm{~F}_{8}$ (pseudophakic patients) gas was injected to tamponade the retinotomy. In more recent cases (nos 10-12) we did not use laser around the retinotomy but used air tamponade only. All patients maintained a strict face down posture postoperatively until the gas bubble resorbed.

\section{CNV HISTOLOGY AND ULTRASTRUCTURE}

For light microscopy, six specimens were fixed in formol-saline and embedded in paraffin. These samples were sectioned for routine staining with periodic acid-Schiff and haematoxylin and eosin. For transmission electron microscopy, five of the six paraffin embedded specimens were trimmed and dewaxed with several changes of xylene. Following hydration, samples were placed in half strength Karnovsky fixative (2\% paraformaldehyde, $2.5 \%$ glutaraldehyde) overnight. Five additional specimens were fixed initially in formol-saline followed by immersion in half strength Karnovsky fixative. Routine postfixation and embedding of all tissue was as follows. Samples were rinsed with several changes of phosphate buffered sucrose and postfixed in $2 \%$ osmium tetroxide. This was followed by rinsing in the same buffered sucrose, dehydration in ethanol, and infiltration into Epon. Tissue was polymerised for 2 days in a $60^{\circ} \mathrm{C}$ oven. For light microscopy, semithin sections were stained with toluidine blue. For transmission electron microscopy, specimens were thin sectioned on a RMC MT-7 ultramicrotome, and sections were placed onto large slot grids. Grids were stained with uranyl acetate and lead citrate. Samples were examined and photographed on a Zeiss EM 10C electron microscope.

\section{Results}

The study group includes 10 men and two women, all white, ranging in age from 61 to 83 years (mean 73 years). The duration of visual symptoms varied from 1 week to 9 years (median 4 months; mean 21 months). All patients had subfoveal CNV with an exudative macular detachment due to AMD, and in all cases the preoperative visual acuity was $\leqslant 20 / 200$. No CNV had been previously treated with laser. Preoperative angiograms revealed CNV composed of classic and occult components (cases 1, 3, 6, 9-12), disciform scars (cases 2, 4, 5), or blocked fluorescence from blood (cases 7,8 ). In some cases (nos 2, $4,5,7$ ) adhesions between the fovea and CNV were evident at the time of surgery. Postoperative follow up averaged 9 months (range 3-21 months) and was greater than 6 months in all but one patient (case 12) who was lost to follow up.

Three cases (nos 1, 6, 8) exhibited normal subfoveal choriocapillaris perfusion postoperatively. Case 2 demonstrated normal subfoveal choriocapillaris perfusion 1 month after surgery but developed a macula off retinal detachment and a cataract which precluded further evaluation of choroidal perfusion.

Abnormal choroidal perfusion was noted in the bed of dissection in eight patients postoperatively (Table 1). One of these patients (case 7) demonstrated delayed choriocapillaris filling. The remaining seven patients (cases 3-5, 9-12) exhibited areas of non-filling of the choriocapillaris as well as areas in which filling was delayed. In two cases (nos 10,12), choriocapillaris filling was documented to be normal 4 days postoperatively but was abnormal by 6 weeks after surgery (Figs 1 and 2). In one of these cases (no 12), only part of the area previously occupied by the CNV displayed choriocapillaris perfusion delay (Fig 2 (15)). One case (no 11) disclosed choriocapillaris atrophy near the retinotomy 3 days after surgery. This area showed choriocapillaris non-perfusion on fluorescein angiography. In the remainder of the dissection bed, choriocapillaris perfusion was unremarkable at this time. By 6 weeks after 
Table 1 Fluorescein angiogram changes following excision of choroidal neovascular membranes

\begin{tabular}{|c|c|c|c|c|c|c|c|}
\hline \multirow[b]{2}{*}{ Patient no } & \multirow{2}{*}{$\begin{array}{l}\text { Age } \\
\text { (years) }\end{array}$} & \multirow{2}{*}{$\begin{array}{l}\text { Duration of } \\
\text { symptoms }\end{array}$} & \multirow[b]{2}{*}{ Pre-op vision } & \multirow[b]{2}{*}{ Post-op vision } & \multirow{2}{*}{$\begin{array}{l}\text { Pre-op } \\
\text { angiogram }\end{array}$} & \multicolumn{2}{|l|}{ Post-op angiogram } \\
\hline & & & & & & First & Final \\
\hline 1 & 82 & 4 months & $6 / 200$ & $20 / 400$ (9 months) & $\mathrm{CNV}^{1}$ & $\mathrm{NL}^{2}$ (1 month) & NL (8 months) \\
\hline 2 & 66 & 2 years & $1 / 200$ & HM 4' (9 months) & Disciform $^{3}$ & NL (1 month) & $\mathrm{NA}^{4}$ \\
\hline 3 & 83 & 2 months & $2 / 200$ & $1 / 200$ (7 months) & $\mathrm{CNV}$ & $\mathrm{ABNL}^{5}$ (1 month) & ABNL (7 months) \\
\hline 4 & 73 & 9 years & HM 6" & NLP (21 months) & Disciform & ABNL (1 month) & $\mathrm{NA}^{4}$ \\
\hline 5 & 82 & 5 years & $20 / 480$ & $20 / 200$ (21 months) & Disciform & ABNL (3 months) & ABNL (21 months) \\
\hline 6 & 72 & 1 year & $20 / 300$ & 10/380 (6 months) & $\mathrm{CNV}$ & NL (2 months) & NL (6 months) \\
\hline 7 & 78 & 6 months & $20 / 480$ & $20 / 400$ (9 months) & Blood $^{6}$ & ABNL (6 weeks) & ABNL (9 months) \\
\hline 8 & 69 & 1 week & $20 / 240$ & $20 / 400$ (6 months) & Blood $^{6}$ & NL (2 weeks) & NL (6 months) \\
\hline 9 & 61 & 6 weeks & $20 / 200$ & $4 / 200$ (6 months) & $\mathrm{CNV}$ & ABNL (4 weeks) & ABNL (6 months) \\
\hline 10 & 80 & 6 months & $4 / 200$ & $3 / 200$ (6 months) & $\mathrm{CNV}$ & NL (4 days) & ABNL (6 weeks) \\
\hline 11 & 54 & 2 months & $20 / 400$ & $20 / 400$ (6 months) & $\mathrm{CNV}$ & $\mathrm{NL}^{7}$ (3 days) & ABNL (6 months) \\
\hline 12 & 75 & 3 months & $6 / 160$ & $7 / 80$ (3 months) & $\mathrm{CNV}$ & NL (4 days) & ABNL (3 months) \\
\hline
\end{tabular}

${ }^{1} \mathrm{CNV}=$ choroidal neovascularisation (classic and occult components).

${ }^{2} \mathrm{NI}=$ normal subfoveal choriocapillaris perfusion.

${ }^{3}$ Disciform $=$ disciform scar.

${ }^{4} \mathrm{NA}=$ not available. Patient developed macula off retinal detachment 6 weeks postoperatively.

${ }^{5} \mathrm{ABNL}=$ abnormal subfoveal choriocapillaris perfusion.

${ }^{6}$ Subretinal blood precluded complete evaluation.

${ }^{7}$ Choriocapillaris atrophy was present near the retinotomy but not in other areas covered by the CNV.

See text for additional details.

surgery, additional areas of choriocapillaris non-perfusion were evident on fluorescein angiography. The tissue excised from this patient showed choriocapillaris at one edge of the specimen (see below).

These perfusion abnormalities were present in seven of the eight ( $88 \%$ ) patients by 6 weeks postoperatively. In the one case (no 5) where this was not observed, the first postoperative angiogram was obtained at 3 months. In all patients, the perfusion abnormalities in areas previously occupied by the CNV were confined to the choriocapillaris. In contrast, choroidal non-perfusion involving small and medium sized vessels regularly accompanied areas of laser treatment surrounding the retinotomy. As proved by comparison with the preoperative fluorescein angiogram, choriocapillaris filling defects developed in areas more than $1000 \mu \mathrm{m}$ from the edge of laser treatment. Because the edge of the CNV can be grasped firmly near the retinotomy, surgical instruments were not introduced more than $750 \mu \mathrm{m}$ into the subretinal space.

The excised CNVs ranged in size from 1500 $\times 1300 \mu \mathrm{m}^{2}$ to $5400 \times 6000 \mu \mathrm{m}^{2}$ (mean $3300 \times$ $3300 \mu \mathrm{m}^{2}$ ). Impaired choriocapillaris filling developed even when the excised CNV was less than $1500 \mu \mathrm{m}$ in diameter. There was no clear correlation between CNV size, duration of symptoms, or degree of CNV fibrosis and the development of abnormal choriocapillaris perfusion.

At the time of the most recent fluorescein angiogram, best corrected visual acuity had improved by two lines or more (on the BaileyLovie chart) in three patients (cases $1,5,12$ ), was unchanged in five patients (cases $3,7,8$, $10,11)$, and had decreased by two or more lines in four patients (cases 2, 4, 6, 9). There was no correlation between visual outcome and the presence of choroidal perfusion defects, but in the two cases (nos 5,12) that showed visual improvement and had abnormal subfoveal choriocapillaris filling, the final visual acuity was $\leqslant 20 / 200$, which is compatible with extrafoveal fixation.
Regarding surgical complications, two eyes (cases 2, 4) developed postoperative retinal detachment with proliferative vitreoretinopathy (grade CP-2), each at 6 weeks. The posterior hyaloid was not excised in these cases. This fact motivated excision of the posterior hyaloid face and washout of the vitreous cavity before fluid-gas exchange in all subsequent cases. A peripheral retinal detachment associated with a dialysis in the meridian of the superonasal sclerotomy occurred in one case (5). All patients underwent anatomically successful retinal reattachment surgery. Subsequently, one patient (case 4) lost light perception following an ophthalmic artery occlusion.

The specimen from one case (no 7) with choriocapillaris perfusion abnormalities was lost during tissue processing. Material was available for light microscopy in 11 cases and for ultrastructural analysis in 10 cases. Because of inadequate fixation, one specimen (case 3) was judged unsuitable for ultrastructural study but showed RPE, thickened Bruch's membrane, and collagen on light microscopy. In the remaining cases, ultrastructural analysis confirmed light microscopic findings and revealed $\mathrm{RPE}$, associated basal laminar deposit, RPE basement membrane, and both fibrillar and wide spaced collagen in all specimens (Table 2 and Figs 3-5). Fibrous tissue constituted a substantial portion of each specimen. Endothelium lined vascular channels were present in eight specimens (nos 2, 4, 5, 8-12) and contained mononuclear inflammatory cells in several cases (nos 4, 9, 11). Vessels were present both internal and external to the RPE layer and were surrounded by a dense collagenous meshwork. Portions of inner Bruch's membrane, defined as material present internal to the elastic lamina up to but not including the RPE basement membrane, were present in six specimens (nos $1,2,4,5,8,11)$. In seven specimens (nos 1, 2, 8-12), a significant discontinuity in the RPE basement membrane was present (Figs 4 (18) and 5 (20)). Whether this represents a surgical cleavage plane between the basal laminar deposit and the RPE basement membrane or is an artefact of tissue 

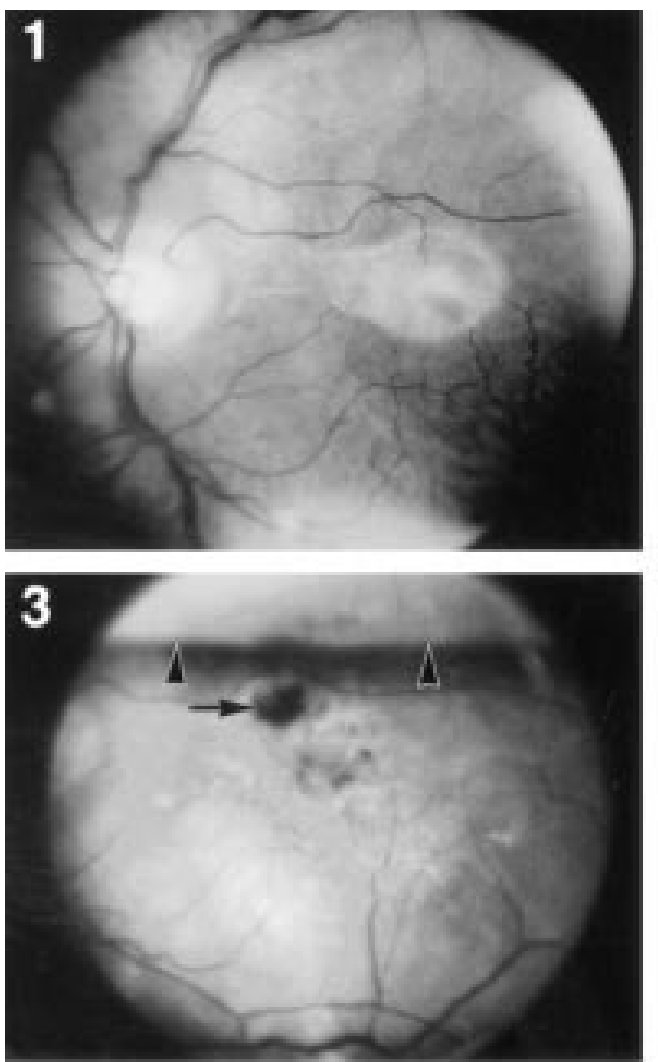

Figure 1 Fluorescein angiographic changes following $C N V$ excision (case 10). (1) Preoperative photograph. Vision $=4 / 200$ (2) Preoperative fuorescein angiographic appearance of CNV. There is blockage of fluorescence by white fibrous-like tissue at the perimeter of the CNV. (3) Postoperative appearance 1 week later. The air bubble meniscus is visible

(arrowheads). There is blood at the retinotomy site (arrow). (4) Late venous phase angiogram shows choroidal perfusion in the area occupied by CNV with punctate areas of blockage due to subretinal blood. (5)

Postoperative appearance 3 months after surgery.

Vision $=3 / 200$. There is epiretinal fibrosis at the retinotomy site (arrow). (6)

Arterial phase angiogram demonstrating markedly delayed choroidal filling in the area previously occupied by the CNV. (7) and (8) Fluorescein dye gradually leaks from the edge of the dissection bed centrally proving choriocapillaris non-perfusion. Comparison of the late venous phase angiograms 1 week (4), 3 months (7), and (8) after surgery demonstrates the change in choriocapillaris perfusion over time.
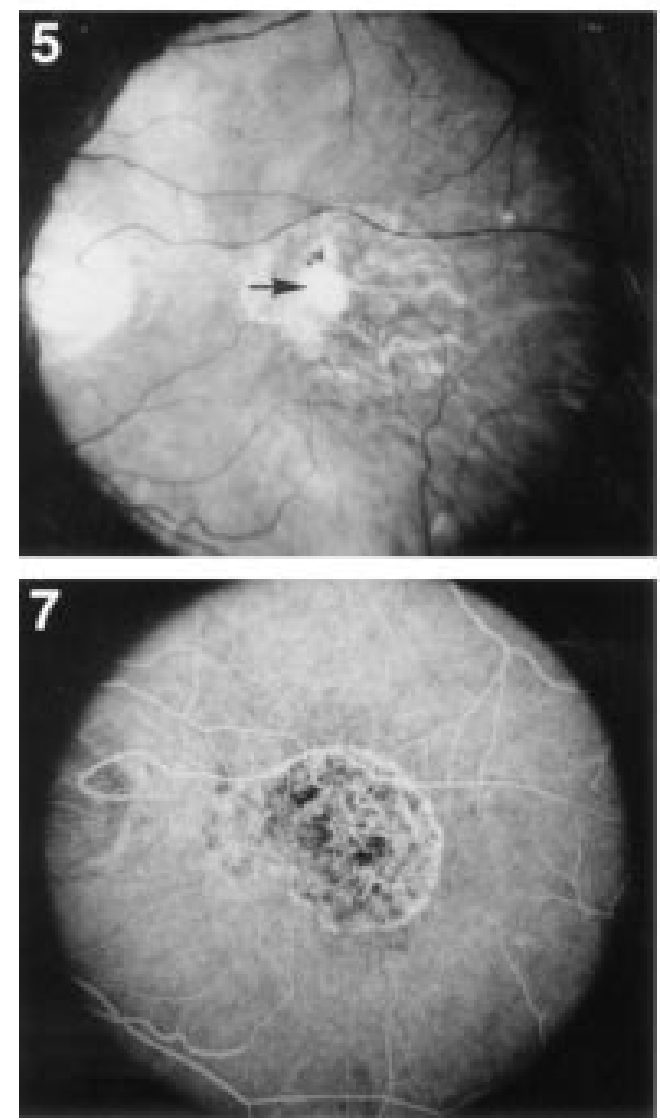
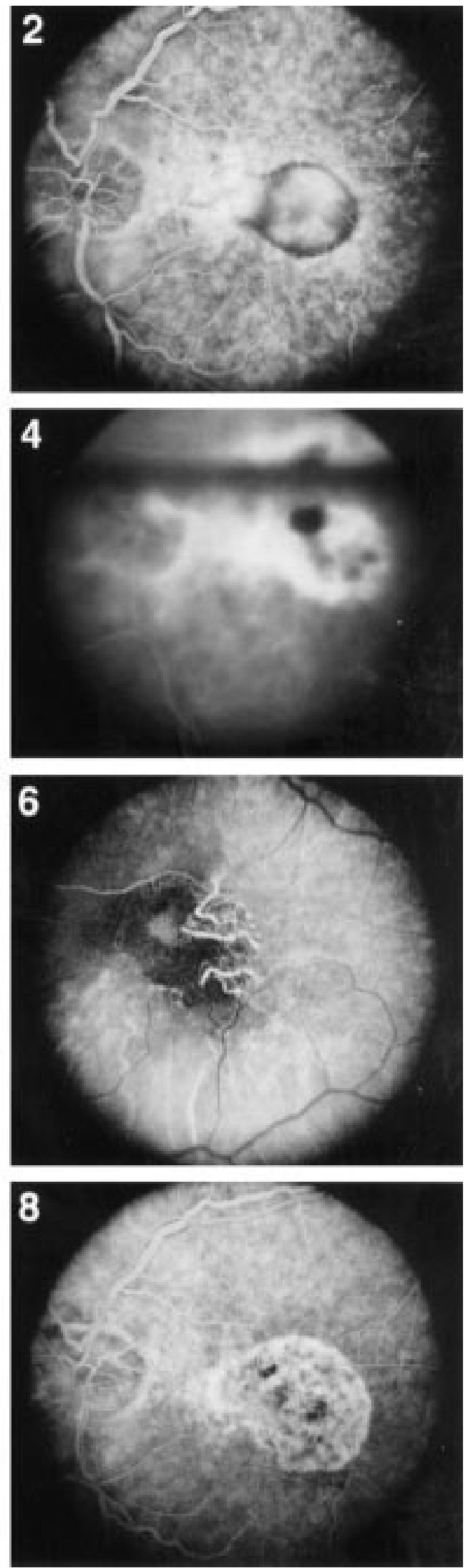


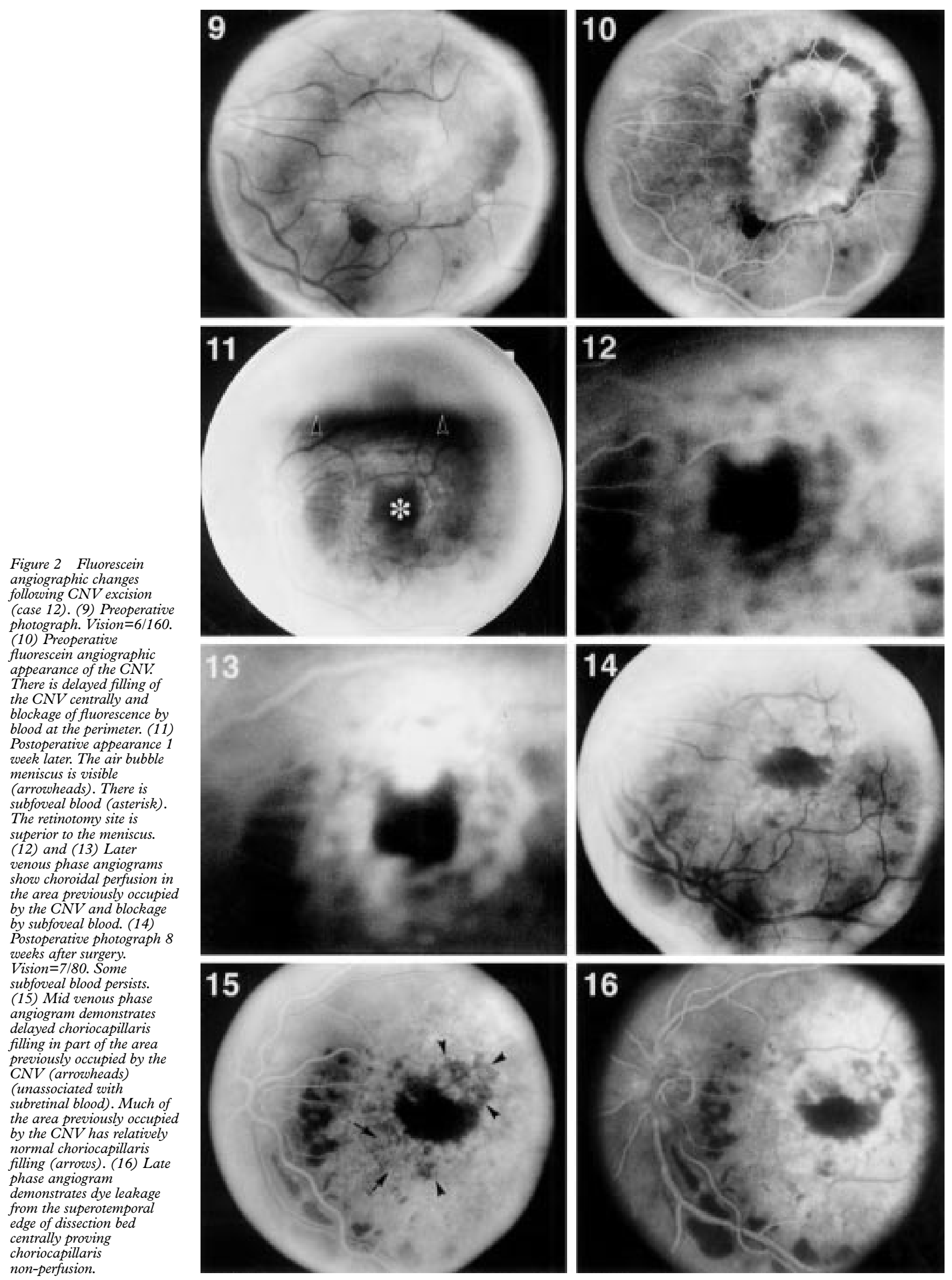


Table 2 Ultrastructure of surgically excised choroidal neovascular membranes

\begin{tabular}{|c|c|c|c|c|c|c|c|c|c|}
\hline $\begin{array}{l}\text { Patient } \\
\text { No }\end{array}$ & $\begin{array}{l}\text { Post-op FA } \\
A B N L\end{array}$ & $R P E$ & Collagen & $\begin{array}{l}\text { Vascular } \\
\text { channels }\end{array}$ & $\begin{array}{l}\text { RPE basement membrane } \\
\text { discontinuous }\end{array}$ & $\begin{array}{l}\text { Inner Bruch's } \\
\text { membrane }\end{array}$ & $\begin{array}{l}\text { Retinal } \\
\text { tissue }\end{array}$ & $\begin{array}{l}\text { Outer Bruch's } \\
\text { membrane }\end{array}$ & Choriocapillaris \\
\hline 1 & - & + & + & - & + & + & + & - & - \\
\hline 2 & - & + & + & + & + & + & + & - & - \\
\hline $3^{\star \star}$ & + & & & & & & & & \\
\hline 4 & + & + & + & + & - & + & - & + & - \\
\hline 5 & + & + & + & + & - & + & - & - & - \\
\hline 6 & - & + & + & - & - & - & - & - & - \\
\hline $7^{\star \star \star}$ & + & & & & & & & & \\
\hline 8 & - & + & + & + & + & + & - & - & - \\
\hline 9 & + & + & + & + & + & - & - & - & - \\
\hline 10 & + & + & + & + & + & - & - & - & - \\
\hline 11 & + & + & + & + & + & + & - & + & + \\
\hline 12 & + & + & + & + & + & - & + & - & - \\
\hline
\end{tabular}

${ }^{\star}$ Vascular channels $=$ endothelium lined vascular channels.

$\star \star$ Not enough tissue for electron microscopy.

$\star \star \star$ Specimen lost.

See text for definition of terms.

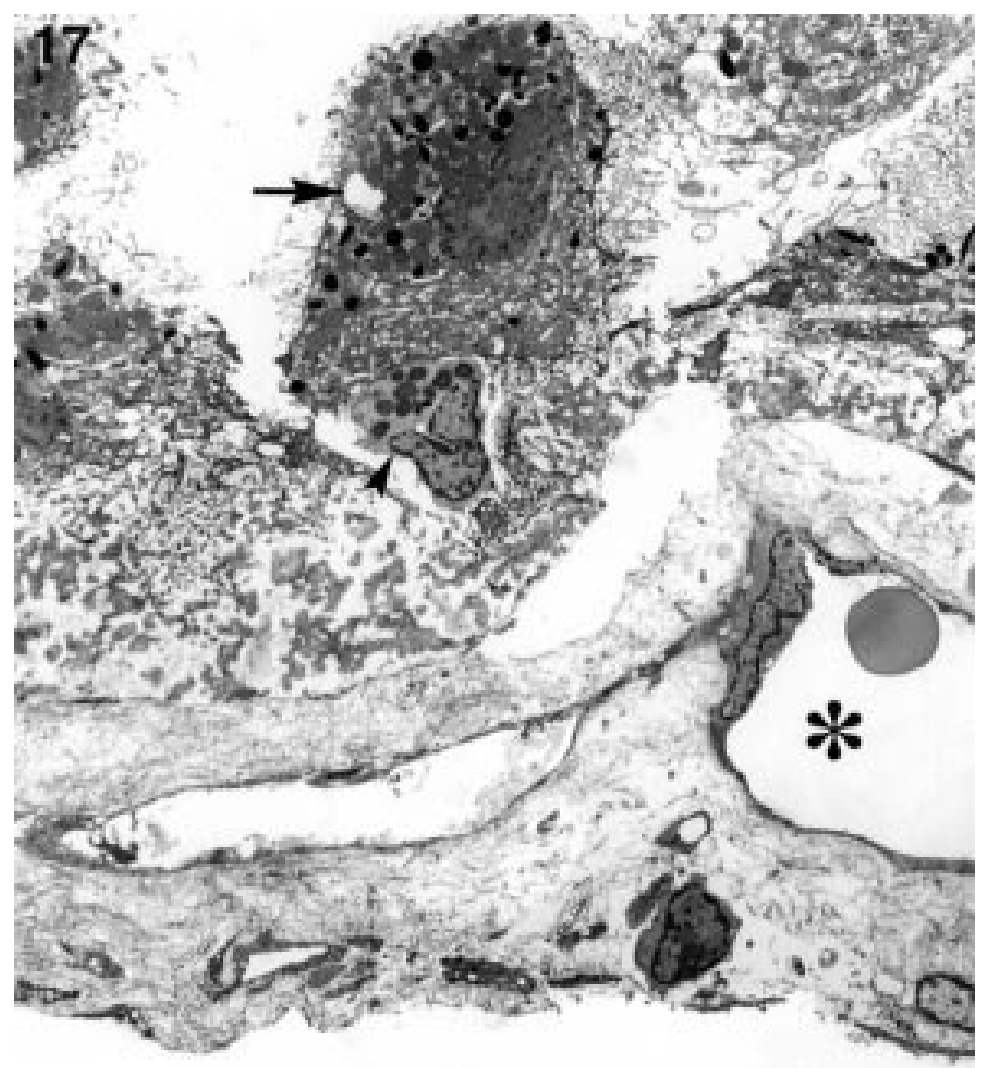

Figure 3 (17) Ultrastructure of excised CNVs. The specimen (case 5) contains RPE (arrow), a macrophage (arrowhead), and a collagen enmeshed, endothelial lined vascular channel (asterisk) external to the RPE. Final magnification $\times 3200$.

processing is unknown. Outer segment fragments (cases 1, 12) and several rows of photoreceptor nuclei adherent to underlying scar tissue (case 2) were identified in some cases.

Outer Bruch's membrane components, including the elastic lamina and the thickened outer collagenous layer, were present in two cases (nos 4,11). Choriocapillaris was identified in one specimen (case 11). The tissue excised from this case was composed mainly of $\mathrm{RPE}$ with underlying basal laminar deposit and discontinuous RPE basement membrane and of overlying vascular channels in a collagenous matrix (Fig 5 (20)). At one edge of the specimen, Bruch's membrane, with underlying choriocapillaris and choroidal melanocytes, was present (Fig 5 (21)). An adjacent area contained RPE, underlying basal laminar and basal linear deposit, and Bruch's membrane with underlying choriocapillaris atrophy (Fig 5 (22)). This case shows that choriocapillaris atrophy may precede CNV excision and that CNV excision may be accompanied by choriocapillaris removal.

As judged from the histology of the excised tissue (Table 2 and Figs 3-5 (17-22), the plane of separation of the CNV from Bruch's membrane varied from specimen to specimen and within specimens and occurred at the level of basal laminar deposit (case 12), at the level of RPE basement membrane (cases 9, 10), at the level of the thickened inner collagenous layer (cases $1-3,5,8$ ), at the level of the thickened outer collagenous layer of Bruch's membrane (case 4), and at the level of the choriocapillaris (case 11).

\section{Discussion}

Choroidal neovascular membranes can be excised using currently available microsurgical instruments, but most patients with AMD do not experience significant visual improvement following surgery. ${ }^{9-12} 15$ The impairment in choriocapillaris perfusion (with secondary photoreceptor atrophy) observed after CNV excision may, in part, underlie these visual results. Preoperative and intraoperative retinal damage may also limit the visual outcome. ${ }^{16}$ Since our preliminary report of choriocapillaris non-perfusion following $\mathrm{CNV}$ excision in AMD patients, ${ }^{17}{ }^{18}$ other investigators have reported similar results both in AMD patients $^{12} 1920$ and in a patient with the ocular histoplasmosis syndrome. ${ }^{21}$ In this report we also show that postoperative choriocapillaris non-perfusion may result from preoperative choriocapillaris atrophy and intraoperative choriocapillaris damage.

Histopathological and clinicopathological reports have demonstrated variability in the integrity of the outer retina and RPE in exudative AMD at various stages in the disease. ${ }^{1622} 23$ Adhesions between the retina and underlying CNV were noted intraoperatively in four patients (cases $2,4,5,7$ ) which suggests that outer retinal degeneration was present preoperatively in these cases. Three of these patients (cases 2, 4, 5) had advanced disciform scars. 

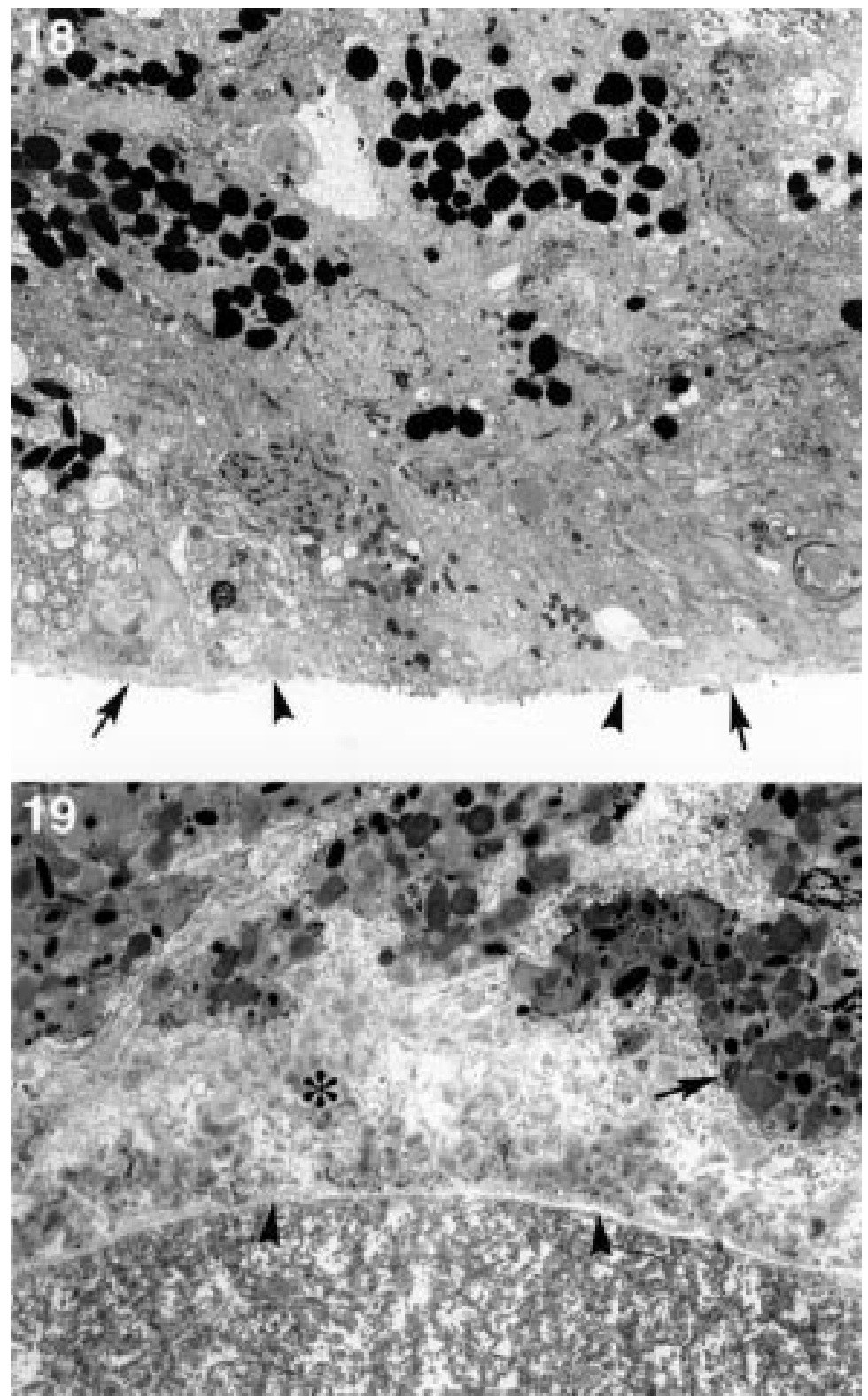

Figure 4 (18) Ultrastructure of excised CNVs. The specimen (case 10) exhibits a cleavage plane at the level of the RPE basement membrane (arrows). There is an apparent discontinuity in the basement membrane in the centre of the specimen (arrowheads). Basal laminar deposit and a probable RPE cell are present above the basement membrane. Basal laminar deposit is present above the area of discontinuity in the basement membrane.

(19) The specimen (case 8) exhibits a cleavage plane at the level of thickened inner Bruch's membrane. Basal laminar deposit (asterisk), RPE (arrow), and RPE basement membrane (arrowheads) are present. Final magnification $\times 3200$.

These patients were offered surgery because a significant exudative macular detachment was present. Two patients (cases 7,8 ) had significant submacular blood which may have caused preoperative photoreceptor degeneration. ${ }^{24-27}$ The remaining patients (nos $1,3,6,9-12)$ were followed as visual acuity declined to $20 / 200$ or worse. We believed the patients might benefit from surgery because the exudative macular detachment could have been a significant cause of visual loss, and/or their CNVs were relatively small ( $\leqslant 2$ disc diameters wide). The goal of surgery in these cases was macular reattachment following removal of the source of exudation with the expectation that surrounding native RPE would repopulate the area of dissection.

In eight of the 12 patients in this report, serial fluorescein angiograms showed impaired choriocapillaris perfusion postoperatively in the area previously occupied by the CNV. Because we used long acting gas tamponade in most cases, we could not assess choriocapillaris perfusion routinely until 3-4 weeks after surgery. In two cases (nos 10,12), however, choriocapillaris filling was documented to be normal several days after surgery but was abnormal 6 weeks later. This time course suggests but does not prove that direct intraoperative trauma to the choroid was not the cause of these changes in these cases. In one case (11) choriocapillaris was present in the excised tissue proving that intraoperative trauma can play a role in the development of choriocapillaris perfusion abnormalities in some patients. Furthermore, this specimen exhibited areas of choriocapillaris atrophy proving that preoperative choriocapillaris atrophy masked by the hyperfluorescence of the CNV may also account for the choroidal non-perfusion seen in some of the cases with long acting gas bubbles. Still, some areas which showed normal choriocapillaris perfusion 1 week after surgery did eventually develop choriocapillaris nonperfusion in this eye.

RPE was present in all analysed surgical specimens, and we posit that removal of RPE at surgery played a role in initiating choriocapillaris perfusion changes, especially in cases 10-12. Ringvold, Korte and coworkers have shown that following selective poisoning of the RPE with intravenous sodium iodate in rabbits, subjacent choriocapillaris atrophies. ${ }^{28} 29$ One week after iodate injection, the choriocapillaris shows ultrastructural abnormalities. Four weeks later, the choriocapillaris is reduced or absent only in areas devoid of RPE and the larger choroidal vessels are spared. ${ }^{29}$ After iodate treatment, RPE regeneration occurs (usually from the far periphery and optic nerve head perimeter). RPE advance along the remnant RPE basement membrane, ${ }^{30} 31$ and regeneration of subjacent choriocapillaris occurs in register. ${ }^{31}$ In our series, impairment of choriocapillaris perfusion in the area previously occupied by the CNV seemed to follow a time course similar to that described for iodate induced choriocapillaris degeneration in laboratory animals. Postoperative choriocapillaris non-perfusion may be indirect evidence for either RPE malfunction or continued absence of RPE in the dissection bed after removal at surgery. Hsu and coworkers $^{32}$ reported a clinicopathological correlation of an eye that had undergone CNV excision. There was incomplete RPE ingrowth in the centre of the dissection, and the subjacent choriocapillaris was acellular. RPE that had grown into the more peripheral part of the dissection bed were attenuated.

Heriot and Machemer described the consequences of localised retinectomy and mechanical RPE debridement in rabbits. RPE repopulate the defect in 7 days. ${ }^{33}$ Before this occurs, however, there is fluorescein leakage from the 

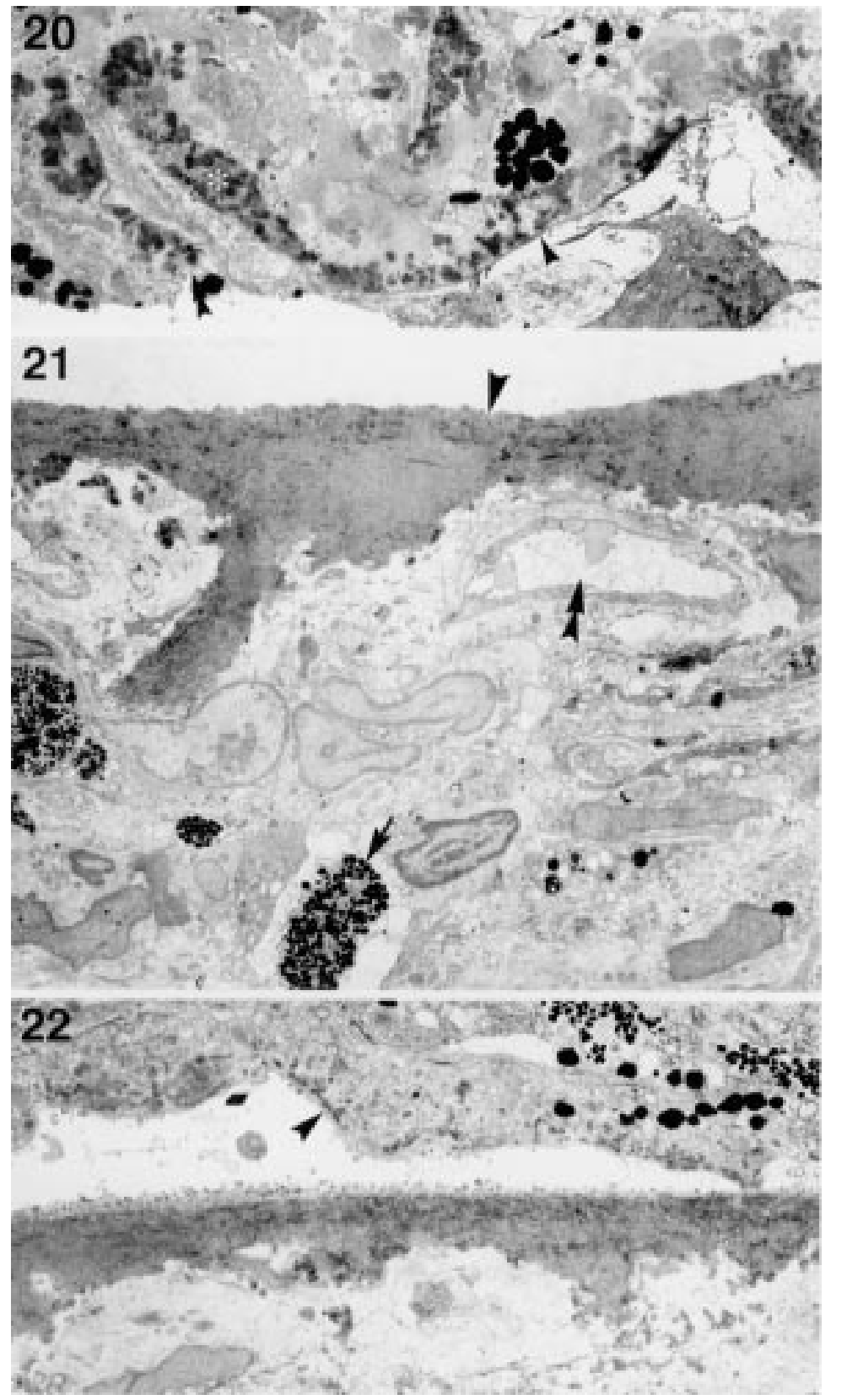

Figure 5 (20) Ultrastructure of excised CNV (case 11). Most of the external plane of dissection is at the level of the RPE basement membrane (arrowhead) which shows foci of discontinuity (double arrowhead) and overlying basal laminar deposit (asterisk). (21) One edge of the specimen (case 11) contains Bruch's membrane (arrowhead), underlying choriocapillaris (double arrowhead), and choroidal melanocytes (arrow). (22) This area (case 11) shows Bruch's membrane with overlying RPE basement membrane (arrowhead) and basal laminar deposit but no underlying choriocapillaris. Final magnification $\times 3200$.

debrided surface, and the choriocapillaris shows ultrastructural evidence of early degeneration. We observed normal choriocapillaris filling with fluorescein leakage in portions of the area previously occupied by the CNV 3-5 days after surgery in three cases (nos 10-12) which subsequently developed impaired perfusion. Four weeks after retinectomy and RPE debridement, the rabbit choriocapillaris calibre is normal and is fenestrated appropriately. ${ }^{33}$ The ability of residual native RPE to repopulate a localised defect rapidly may account for the different observations in the iodate and mechanical debridement experiments. Repopulation of the $\mathrm{CNV}$ dissection area by functional RPE could explain why changes in choroidal perfusion were not observed in all cases. The presence of perfused and nonperfused choriocapillaris in case 12 suggests that there may be postoperative microheterogeneity of the RPE and choriocapillaris relation within the dissection bed.

Choriocapillaris perfusion abnormalities and choriocapillaris atrophy are recognised as a complication of several abnormal conditions involving the RPE including retinitis pigmentosa, ${ }^{34}$ atrophic AMD,,$^{35}$ and RPE tears. ${ }^{1622}{ }^{37-39}$ The presence of choriocapillaris perfusion abnormalities following CNV excision implies that, in some cases, the cells which repopulate the dissected surface of Bruch's membrane cannot sustain normal choriocapillaris and/or that 'normal' RPE cells repopulate the dissection bed abnormally or incompletely. Senescence or disease of the RPE, or perhaps unfavourable features of the denuded surface of Bruch's membrane, might prevent normal repopulation of the area previously occupied by the CNV. In a study of 123 excised CNVs, Grossniklaus and coworkers ${ }^{19}$ found that Bruch's membrane fragments were present in specimens from five of the 11 patients who developed postoperative choriocapillaris atrophy (nine of the 11 had RPE). Portions of the $\mathrm{RPE}$ basement membrane and inner collagenous layer of Bruch's membrane (and occasionally even the elastic lamina) were also present in the excised neovascular complexes in our patients, suggesting that the surface on which the RPE at the perimeter of the dissection must grow is abnormal. Pauleikhoff, Piguet and coworkers, and Bird have proposed that in AMD prolonged choroidal filling on fluorescein angiography may result from thickening of and changes in the biochemical composition of Bruch's membrane. ${ }^{40-42}$ Abnormalities in Bruch's membrane or in the extracellular matrix might also have played a role in the postoperative appearance of the fluorescein angiogram by impairing the normal metabolic interaction between the repopulating cells and the choriocapillaris.

In summary, we found that choriocapillaris non-perfusion was present in eight of 12 patients with AMD after surgical excision of subfoveal CNVs. Ultrastructural analysis of the available excised tissue revealed RPE in all cases examined and choriocapillaris in one. We hypothesise that the choriocapillaris perfusion abnormalities can be present preoperatively or can arise as a result of intraoperative trauma or as a consequence of the removal of RPE that almost always accompanies CNV excision in AMD. If the last hypothesis is correct, then these clinical data provide indirect evidence that native RPE at the edge of the dissection either do not always repopulate the dissection area adequately and/or that their ability to support the underlying choriocapillaris is compromised. If RPE repopulation of the dissection area is abnormal, then techniques which promote RPE repopulation of the dissection bed such as RPE transplantation, adjuvant growth factor therapy, or biochemical 'reconstitution' of the dissection bed may be useful 
adjuncts to surgical CNV excision. Regardless of the aetiology, when subfoveal choriocapillaris non-perfusion occurs, it will probably limit visual outcome following surgery for AMD because of accompanying photoreceptor atrophy.

Supported in part by That Man May See, Inc, The Foundation Fighting Blindness, Research to Prevent Blindness, Inc, and the Heed Ophthalmic Foundation (to M A Nasir 1994-5).

Presented in part at ARVO Annual Meeting, Sarasota, Ophthalmology, Chicago, Illinois, November 1993.

1 Macular Photocoagulation Study Group. Argon laser photocoagulation for senile macular degeneration. Result of a randomized clinical trial. Arch Ophthalmol 1982;100:912-8.

2 Macular Photocoagulation Study Group. Argon laser photocoagulation for neovascular maculopathy. Three-year results from randomized clinical trials. Arch Ophthalmol 1986;104:694-701.

3 Macular Photocoagulation Study Group. Krypton laser photocoagulation for neovascular lesions of age-related macular degeneration. Results of a randomized clinical macular degeneration. Results of a ran

trial. Arch Ophthalmol 1990;108:816-24.
4 Macular Photocoagulation Study Group. Laser photocoMacular Photocoagulation Study Group. Laser photocoagulation of subfoveal neovascular lesions of age-related
macular degeneration. Updated findings from two clinical macular degeneration. Updated findings

5 Macular Photocoagulation Study Group. Subfoveal neovascular lesions in age-related macular degeneration. Guidelines for evaluation and treatment in the Macular Photocoagulation Study. Arch Ophthalmol 1994;112:489-99.

6 Macular Photocoagulation Study Group. Recurrent choroidal neovascularization after argon laser photocoagulation for neovascular maculopathy. Arch Ophthalmol 1986;104: 503-12.

7 Macular Photocoagulation Study Group. Persistent and recurrent neovascularization after krypton laser photocoagulation for neovascular lesions of age-related macular degeneration. Arch Ophthalmol 1990;108:825-31.

8 Macular Photocoagulation Study Group. Laser photocoagulation of subfoveal recurrent neovascular lesions in agerelated macular degeneration. Results of a randomized clinical trial. Arch Ophthalmol 1991;109:1232-41.

9 Lambert HM, Capone A Jr, Aaberg TM, Sternberg P Jr, Mandell BA, Lopez PF. Surgical excision of subfoveal neovascular membranes in age-related macular degeneration. Am $\mathcal{f}$ Ophthalmol 1992;113:257-62.

10 Thomas MA Dickinson JD, Melberg NS, Ibanez HE Dhaliwal RS. Visual results after surgical removal of subfoveal choroidal neovascular membranes. Ophthalmology 1994;101:1384-96.

11 Berger AS, Kaplan HJ. Clinical experience with the surgical removal of subfoveal neovascular membranes. Ophthalmology 1992;99:969-76.

12 Ormerod LD, Puklin JE, Frank RN. Long term outcomes after surgical removal of advanced subfoveal neovascular membranes in age related macular degeneration. Ophthal molgy 1994;101:1201-10.

13 Fung WE. Interferon alpha 2a for treatment of age-related macular degeneration. Am f Ophthalmol 1991;112:349-50.

14 Chakravarthy U, Houston RF, Archer DB. Treatment of age-related subfoveal neovascular membranes by teletherapy: a pilot study. Br f Ophthalmol 1993;77:265-73

15 Thomas MA, Kaplan HJ. Surgical removal of subfoveal neovascularization in the presumed ocular histoplasmosis syndrome. Am f Ophthalmol 1991;111:1-7.

16 Green WR, Enger CS. Age-related macular degeneration histopathologic studies. Ophthalmology 1993;100:1519-35.

17 Nasir M, Zarbin MA. Choriocapillaris atrophy as a complication of surgical excision of choroidal neovascular membranes. Invest Ophthalmol Vis Sci 1993;34:653.
18 Zarbin MA, Nasir M. Impaired choriocapillaris perfusion following subfoveal surgery for macular degeneration. Ophthalmologia 1993;100(9A):97.

19 Grossniklaus HE, Hutchinson AK, Capone A, Woolfson J, Lambert HM. Clinicopathologic features of surgically excised choroidal neovascular membranes. Ophthalmology 1994;101:1099-111.

20 Hudson HL, Frambach DA, Lopez PF. Relation of the functional and structural fundus changes after submacular surgery for neovascular age-related macular degeneration. surgery for neovascular age-related

21 Desai VN, Del Priore LV, Kaplan HJ. Choriocapillaris atrophy after submacular surgery in presumed ocular histoplasmosis syndrome. Arch Ophthalmol 1995;113:408-9.

22 Green WR, McDonnell PJ, Yeo JH. Pathologic features of senile macular degeneration. Ophthalmol 1985;92:615-27.

23 Small ML, Green WR, Alpar JJ, Drewry RE Jr. Senile macular degeneration. A clinicopathologic correlation of wo cases with pigment epithelium. Arch Ophthalmol 1976;94:601-7.

24 Bennett SR, Folk JC, Blodi CF, Klugman M. Factors prognostic of visual outcome in patients with subretinal hemorrhage. Am f Ophthalmol 1990;109:33-7.

25 Glatt H, Machemer R. Experimental subretinal hemorrhage in rabbits. Am $\mathcal{7}$ Ophthalmol 1982;94:762-73.

26 Lewis H, Resnick SC, Flannery JG, Straatsma BR. Tissue plasminogen activator treatment of experimental subretinal hemorrhage. Am f Ophthalmol 1991;111:197-204.

27 Toth CA, Morse LS, Hjelmeland LM, Landers MB III. Fibrin directs early retinal damage after experimental subretinal hemorrhage. Arch Ophthalmol 1991;109:723-9.

28 Ringvold A, Olsen EG, Flage T. Transient breakdown of the retinal pigment epithelium diffusion barrier after sodium iodate: a fluorescein angiographic and morphologic study in the rabbit. Exp Eye Res 1981;33:361-9.

29 Korte GE, Reppuci V, Henkind P. RPE destruction causes choriocapillary atrophy. Invest Ophthalmol Vis Sci 1984;25: 1135-45.

30 Pollack A, Korte GE. Repair of retinal pigment epithelium and its relationship with capillary endothelium after krypton laser photocoagulation. Invest Ophthalmol Vis Sci 1990;31:890-8.

31 Korte GE. Choriocapillaris regeneration in the rabbit: ultrastructure of the new endothelial tube formation. Invest Ophthalmol Vis Sci 1989;30:1938-50.

32 Hsu, JK, Thomas, MA, Ibanez, H, Green, WR. Clinicopathologic studies of an eye after submacular membranectomy for choroidal neovascularization. Retina 1995;15:4352.

33 Heriot WJ, Machemer R. Pigment epithelial repair. Graefes Arch Clin Exp Ophthal 1992;230:91-100.

34 Hyvärinen L, Maumenee AE, Kelley J, Cantollino S. Fluorescein angiographic findings in retinitis pigmentosa. Am $\mathcal{F}$ Ophthalmol 1971;71:17-26.

35 Schatz H, McDonald HR. Atrophic macular degeneration. Ophthalmology 1989;96:1541-51.

36 Sarks JP, Sarks SH, Killingsworth MC. Evolution of geographic atrophy of the retinal pigment epithelium. Eye 1988;2:552-77.

37 Chuang EL, Bird AC. Repair after tears of the retinal pigment epithelium. Eye 1988;2:106-13.

38 Murphy RP, Yeo JH, Green WR, Patz A. Dehiscences of the pigment epithelium. Trans Am Ophthalmol Soc 1985;83:6381

39 Green WR. Clinicopathologic studies of treated choroidal neovascular membranes. Retina 1991;11:328-56.

40 Pauleikhoff D, Chen JC, Chisholm IH, Bird AC. Choroidal perfusion abnormality with age-related Bruch's membrane change. Am f Ophthalmol 1992;109:211-7.

41 Piguet B, Palmvang IB, Chisholm IH. Evolution of age-related macular degeneration with choroidal perfusion abnormally. Am f Ophthalmol 1992;113:657-63.

42 Bird AC. Bruch's membrane change with age. Br f Ophthalmol 1992;76:166-8. 